REVISTA CHILENA DE LITERATURA

Abril 2009, Número 74, 225 - 239

\title{
A PROPÓSITO DE LA "DIFERENCIA": POESÍA DE MUJERES MAPUCHE ${ }^{1}$
}

\author{
Fernanda Moraga \\ Universidad de Santiago de Chile \\ ojosaura@hotmail.com
}

\section{A MODO DE INTRODUCCIÓN}

La escritura poética de mujeres mapuche, dentro de una perspectiva de las identidades, concurre en unos cruces entre género y etnicidades que resultan fundamentales en su relación con la construcción de subjetividades "diferentes", las que pervierten los estereotipos impuestos por el sistema occidental colonizador. La inscripción de esta escritura en la producción literaria chilena actual y en los estudios académicos permite problematizar las disposiciones tradicionales y/o canónicas del mismo, es decir, estas literaturas mapuche intervienen un dominio que, lenta, pero inevitablemente, se desprensa. Además, esta significación de intervención en la percepción homogénea, tanto a nivel cultural general, como a nivel específico de producciones literarias en Chile, da cuenta de una elaboración poética, prácticamente desatendida, tanto por la crítica literaria como por la academia en general (me refiero específicamente a la producción poética de mujeres mapuche y de origen mapuche $)^{2}$. Por lo que la percepción medular en este texto, es que

1 Este trabajo forma parte del Proyecto "Hablas escritas de cuerpos de la ajenidad: Poesía de mujeres mapuche", N N 2070947, Departamento de Investigación Científica y Tecnológica (DICYT) de la Universidad de Santiago de Chile (2007-2008), proyecto del cual soy la investigadora responsable. Una primera versión de éste fue leído en el Coloquio Internacional: Literaturas mestizas en América Latina: estética e ideología. Poitiers, Francia, 17 al 19 de octubre de 2007

2 Esto no significa que no haya estudios y/o aproximaciones importantes dentro de los estudios literarios, respecto a la poesía de mujeres mapuche. Por ejemplo, Claudia Rodríguez de la Universidad Austral de Valdivia ha organizado por dos años consecutivos (2005 y 2006) el "Encuentro de Escritoras Mapuches: Domo Dungun: Palabras de Mujer", apoyada por la misma Universidad. Además, el año 2006 se publicó la primera antología de poesía de mujeres 
existen diversas circunstancias de construcción de identidades en Chile y que hay un corpus de textos poéticos con diferentes grados referenciales de origen mapuche que expresan y señalan, no sin intención, esos intensos y complejos giros culturales a partir de subjetividades emergentes en todas las representaciones de la realización simbólica: emisoras-es, receptoras-es, agenciamientos, estrategias discursivas, que franquean la forma o las formas en que la construcción cultural dominante delimita subjetividades individuales y colectivas, a través de imágenes y múltiples dispositivos simbólicos que confirman identidades y experiencias dentro de los procesos de homogeneización. Por ejemplo, algunas nociones de uso común dentro de los estudios literarios y otras disciplinas afines son utilizadas de manera indiferenciada. Me refiero, fundamentalmente, a la problemática de las "identidades" y de las "etnicidades", las que aparecen como contenidos evidentes e inmediatamente reconocibles, suponiendo de antemano que estas categorías se explican por sí solas, sobre todo cuando se trata de grupos y producciones estéticas de origen indígena. Lo mismo sucede con la categoría de "género" en su estructura de construcción cultural tradicional que alude básicamente a "las mujeres", imponiendo un carácter de borradura con los varones y principalmente, en este caso, una borradura o tachadura de las diferencias entre las mismas mujeres, por lo tanto, implícitamente, la noción de "género" establecería un trascendental de "la mujer". Esto correspondería, en palabras de Judih Butler a una "naturalización en el contexto de un cuerpo" (1990), la que estaría vinculada a una visión de género que es mucho más restrictiva de lo que suponíamos. Por lo tanto, insisto en que existen construcciones identitarias en movimiento que se "incorporan" (uso la palabra "incorporar" en un doble sentido, de 'entrar' y de 'tomar cuerpo', es decir hacerse visible y situarse), dentro de múltiples interdisposiciones entre cultura, género y etnia en las construcciones sociosimbólicas de las "alteridades" de la cultura ${ }^{3}$. Estas representaciones de alteridades en textos poéticos de mujeres mapuche confluyen en procesos identitarios plurales en su configuración y dentro de un contexto de producción literaria en su mayoría, altamente referencial. En este sentido, me refiero a que en general, la poesía mapuche y de origen mapuche hace presente y/o realiza por entre la escritura, fundamentalmente, una concepción cultural particular que concierne a un imaginario cosmovisional y ancestral del pueblo mapuche, incluyendo sus diferencias respecto a sus identidades territoriales: huilliche, pewenche, lafkenche, mapuche e incluso las producciones provenientes del

mapuche, donde se incluyen siete poetas: Hilando en la memoria. 7 mujeres mapuche, editada por Soledad Falabella, Alison Ramay y Graciela Huinao.

${ }^{3}$ En este sentido, no me refiero al reducto de alteridad genérica que establecen los sistemas de homogeneización, sino que a una "alterización" que las poetas agencian en la escritura y con la que están transformando, al mismo tiempo, las circunstancias de esa alteridad prearmada y los patrones normativos a partir de las cuales esa misma alteridad se establece. Es decir, sus escrituras promueven la movilización de nuevas dimensiones en la "alterización", al señalar especificidades en la construcción de diferencias identitarias. 
Puelmapu y no tan solo del Gulumapu ${ }^{4}$. Se trata de textos poéticos que dan cuenta de una emergencia y una evidencia de una sociedad cultural y política más plural en nuestro país, y al mismo tiempo, dan cuenta del ingreso consecuente de nuevas sujetos e identidades culturales en el escenario actual. Las poetas mapuche utilizan la escritura como instrumento (impuesto, pero reapropiado, recordemos que el pueblo mapuche era una cultura ágrafa) de comunicación, de revitalización, de reivindicación, de creación literaria, para (re)construir subjetividades en y desde diferentes cruces, en y desde diferentes entremedios culturales. Desde allí se entrelazan culturas en permanente movimiento en nuevas y diversas formas de posicionar los cuerpos, las identidades, las experiencias y los textos. En este mismo sentido entonces, las poetas destejen un proceso de conciencia impuesto que "deshace" sus experiencias, al mismo tiempo que ellas, las poetas, "deshacen" 5 las normativas impuestas en términos de género y de etnicidad, es decir sus escrituras son conscientes de una afectación de la norma occidental colonialista, primero española y luego chilena.

En este lugar, sus representaciones escriturales agencian un desplazamiento crítico que libera las diferencias, a través de una anacronía constitutiva en sus movimientos e interrogaciones a y desde las sujetos experienciales activadas en las metáforas lingüísticas de sus textos ${ }^{6}$. Se puede mencionar que existen diversas estrategias de vinculación y distanciamiento entre las identidades que transitan por los diferentes textos y las intenciones respecto al posicionamiento que establecen en referencia a la cultura mapuche ${ }^{7}$.

4 El Puelmapu hace referencia a los territorios mapuche del este, es decir, corresponde a los territorios mapuche en Argentina y el Gulumapu, a los territorios mapuche del oeste y que se encuentran en Chile.

5 Tomo este juego de palabras de Judith Butler. Butler hace referencia, por un lado, a las normas que "deshacen" a la persona y por otro lado, "deshacer" las normas para poder habitar mejor. En Deshacer el género.

6 Para Hommi Bhabha esta anacronía o "desfase temporal constituye el retorno del sujeto agente como la agencia interrogativa en la posición catacrésica. Ese espacio disyuntivo de temporalidad es el lugar de la identificación simbólica que estructura el campo intersubjetivo, el campo de la otredad y lo social, donde "nos identificamos con el otro precisamente en un punto en el cual es inimitable, en el punto que elude el parecido"' (Hommi Bhabha, El lugar de la Cultura 225).

7 Al respecto, la poeta mapuche-pewenche Maribel Mora Curriao señala al menos 3 líneas posibles dentro de la producción poética mapuche actual: una primera línea trataría de una poesía que en un primer momento se articula fuertemente a una tradición occidental, para luego girar hacia una "propuesta de oralitura". Una segunda posibilidad, es una poesía que, dice la autora, "desde una visión y una realización del discurso y la lengua propios (se) construye (una) propuesta poética a modo de traducción o versión. Esta poesía está estrechamente relacionada con el ül (canto mapuche) y otros discursos tradicionales mapuche como el nütram (conversación, relato) que tratan de ser incorporados a la textualidad poética moderna, tomándose para ello de los elementos que resulten estéticos en la lengua otra (en este caso el castellano)." Y finalmente, la poeta plantea una "tercera línea de escritura (que) sería aquella 
Por un lado, hay poetas que utilizan un discurso político de contingencia que aparece durante la dictadura militar, por ejemplo, la escritura poética de María Teresa Panchillo. Hoy, este discurso político se reinstala en la poesía de mujeres mapuche como sustrato reivindicativo, en directa relación con los acontecimientos y las demandas de territorio y autonomía del pueblo mapuche (algunos poemas de Eliana Pulquillanca, la poesía de Küyen y de Carmen Curiche).

También están aquellos textos que localizan una mirada que se emplaza en una memoria ancestral, haciendo surgir intensamente un sentido de nostalgia por lo que se perdió y no es posible recuperar. Dentro de esta perspectiva, los dispositivos escriturales recurren, fundamentalmente, al origen ancestral, cosmovisional y territorial no contaminado de la cultura mapuche (Graciela Huinao, Cecilia Nahuelquín, Faumelisa Manquepillán). En este lugar de producción poética, se producen cruces importantes con el imaginario de un pasado reconstituyente que se superpone al presente intoxicado, representado dentro de la escritura, al mismo tiempo, como 'un mundo posible' y como un mundo mitificado y/o idealizado de la cultura (María Isabel Lara, Jacqueline Caniguán, Küyen, Ayliñ Namkucheo).

Por otra parte, surgen escrituras como las de Adriana Paredes Pinda, Maribel Mora Curriao, Miriam Torres Millán, Liliana Ancalao y Roxana Miranda Rupailaf, que con diferentes matices y desenvolturas escriturales presentan cuerpos subjetivados en tensión, asumiendo experiencias, muchas veces, colmadas de contradicciones, las que emergen justamente, como posibilidades de desplazamientos en la iteración cultural colonialista ${ }^{8}$, es decir, justamente, este señalamiento de unas identidades problematizadas, mestizadas es una de las condiciones de su posibilidad cultural. Dentro de estas disposiciones agenciadas de subjetividades poéticas en conflicto, me detendré de manera general y aproximativa en la escritura de Roxana Miranda Rupailaf, de Maribel Mora Curriao y de Adriana Paredes Pinda.

que abiertamente asume la poesía moderna y la condición de poeta para incorporar allí los elementos residuales de su propia cultura..., (es decir), una poética que aunque anclada a lo étnico, no se detiene en la construcción de una identidad idealizada o desproblematizada. Se trata más bien de dar cuenta de la diversidad interna de una realidad étnica conflictuada por la historia". En Maribel Mora, "Poesía mapuche: la instalación de una mismidad étnica en la literatura chilena" (21-22).

8 Al respecto, Butler escribe: "Que mi agencia esté repleta de paradojas no significa que sea imposible. Significa solo que la paradoja es la condición de su posibilidad. Como resultado, el 'yo' que soy se encuentra constituido por normas y depende de ellas, pero también aspira a vivir de maneras que mantengan con ellas una relación crítica y transformadora” (16). 


\title{
ROXANA MIRANDA RUPAILAF: LA SUBVERSIÓN DEL DESEO
}

La escritura de Roxana Miranda Rupailaf desenvuelve emociones que se instalan en el escenario de la intersubjetividad, desde donde se produce un encuentro, un contacto, un cruce entre lo propio y lo ajeno. Específicamente, en su libro Seducción de los venenos ${ }^{9}$, la sujeto es el cuerpo de las serpientes que señalan voces plurales a través de la circulación de los "venenos" contenidos en ellas. De esta forma, los venenos, como el lugar y metáfora del deseo, van confluyendo en movimientos de unos erotismos y parimientos de sujetos fragmentadas. Se trata del deseo en subversión, porque el veneno es el movimiento de la seducción pero también de la muerte. Es ahí donde se realiza la puesta en escena de las emociones de la sujeto y/o de las sujetos de los poemas, tornándose (los venenos-deseos) en sentidos de "transgresión" ${ }^{10}$. Desde esta posición, se derriba el fundamento que encubre el deseo de los cuerpos en un rictus dominante que tiende a la captura del erotismo dentro de un constructo cultural. En tal sentido, las pulsiones venenosas de la sujeto (la serpiente), constituyen la fuga, son el intersticio, el punto de pliegue y despliegue desde donde se revoluciona el deseo en veneno, es decir, se desnuda su significación armada, se pluraliza, se libera en la apropiación de la escritura para mostrar su represión. Este proceso de liberación, en la escritura de Roxana Miranda se revitaliza en la subversión del deseo en los cuerpos cercados de las mujeres bíblicas (serpientes de sal): Eva, Dalila, la mujer de Lot, María Magdalena y la serpiente del Edén. Esto provoca un cruce intertextual, desde donde se posiciona la seducción, la desobediencia, la dislocación y finalmente la explosión de un ansia del placer que se moviliza inyectando el brebaje que desatora el goce sensual de estos cuerpos de mujer: "Muérdete a la carne / y haz el jugo espeso / mezclándolo con sal". Se produce así la provocación de una polifonía de voces y de cuerpos que se cruzan a sí mismos y con otros. El movimiento del deseo erótico (como pulsión consciente que transforma los cuerpos en alteridades), se va construyendo desde la reproducción de las serpientes como mecanismo de explosión permanente de la subversión (serpientes de tierra):

\author{
Nueve meses las albergo \\ $\mathrm{y}$ tres son los que demoro \\ en sacarles el ritmo, \\ en cortarlas
}

9 El libro cambió de nombre al ser publicado: Pu llimeñ ñi rulpázuamelkaken. Seducción de los venenos, 2009.

10 Utilizo la noción de "transgresión" no en el sentido que la usa la tradición: prohibición/transgresión, sino que en el sentido de "rebeldía” planteado por Julia Kristeva: “...calar más hondo, ....ir en otras direcciones, ....interpretar. La interpretación, tal como la entiendo, es una rebeldía.... Es decir, transgresión como el gesto de rebeldía, como el movimiento crítico que debe realizar nuestra conciencia para no confiar en las 'apariencias' y categorías del mundo simbólico" (Julia Kristeva, Sentido y sinsentido de la rebeldía. Literatura y psicoanálisis 11). 
de mis piernas.

En salírseme serpientes

En mis tripas atadas a los ojos

(...)

silencio en que me crecen

$y$ en que crezco.

Roxana Miranda nos señala así, en su texto, la multiplicación de los modos de existir, de la heterogeneidad de las experiencias que conforman la subjetividad de los cuerpos. Una subjetividad que no es una, sino que se construye a través de retazos culturales en permanente dinamismo, contacto e interlocución: "Me dejo abrir las pieles / me ondulo / en el soplo de tus voces". Este lugar de la subjetividad y de la experiencia también es lugar del fracaso de la serpiente que se instala en otra forma del deseo ('serpientes de agua'), el de diluirse, de vaciar las emociones hacia fuera: "Agua hacerte y agrietarte / por las pieles", porque su experienciar en el placer, en el encuentro con el erotismo, en la exploración del cuerpo, también se transforma en corte, en imposibilidad, porque finalmente “...se atora de una ausencia / de líquidos y mieles". De este modo, todas son serpientes, son cuerpos de mujeres que "reclaman su espacio en la geografía de los venenos" (en palabras de la misma poeta), es decir, las metáforas del veneno y de la serpiente, se constituyen en imágenes de subversión que sitúan los cuerpos desde diferentes expresiones de la experiencia, como lugar de contradicciones, como lugar de construcción problemática, de encrucijada no a resolver, sino como territorio de existencia que se asume, que se posiciona y se señala.

De esta forma, la escritura de Roxana Miranda aborda expresamente cuestiones de género, fundamentalmente referidas a la explosión de una sexualidad oprimida, pero que al mismo tiempo, sigue bajo la vigilancia de un sistema de sexo-género construido por las diferentes 'máquinas sociales' a través del tiempo. Además, desde y por entre este territorio de subversión, su escritura va conformando sujetos fronterizas, al distender un anclaje con espacios de sincretismo, de "amasamiento" cultural y religioso, tanto con el mito judeo-cristiano (serpiente de sal), como con el relato originario del pueblo mapuche (serpiente de tierra y serpiente de agua): "sangre corre por los dientes / que no pudieron apretar lo suficiente / cuando pasaron / náufragos azules / en la sal" ("muerdo tierra en los rincones de lo azul"). Por lo que estas sujetos fronterizas se construyen en conciencias tensionadas en el cruce cultural que está contenido y manifiesto en la crítica al malestar de una pesadez de la cultura hegemónica judeo-cristiana "que tanto daño nos ha hecho a los mapuche y los no mapuche"11

La articulación en que estos espacios de juntura se encuentran y desencuentran a la vez, es el despliegue del lugar fronterizo del cuerpo y las voces situadas en el relato poético a través de la bisagra carnal y 'consanguínea de los venenos'; es decir, el deseo

11 Comentario de la poeta Roxana Miranda Rupailaf, en directa referencia a la religión judeo-cristiana. 
de sí misma y de las otras que traen y contienen su deseo, su parentesco corporal y erótico y que va a producir consecuentemente, sujetos situadas en los fracturas de las experiencias y de las culturas. Subsiste aquí la presencia de una conciencia diferente que sigue produciéndose a través de un circuito cultural distinto, el de una "conciencia fronteriza".

\section{MARIBEL MORA CURRIAO: LA ESCENA ESCRITURAL DEL DELIRIO}

En la poesía de Maribel Mora, Perrimontún ${ }^{12}$, surge una sujeto interna y desolada, que distiende en la escritura una subjetividad que se hace y rehace permanentemente de manera profunda y escindida. El lugar de su experiencia moviliza las grietas de su cuerpo cultural: "Mira el sello de mi cuerpo, / pero no levantes el velo / de mi soledad sin memoria".

En este fragmento del poema "Tuwin Malen"13, la sujeto se sitúa en origen corporal deseante, se nombra mujer que desciende de las aguas como sustrato del deseo, de la voluntad de la experiencia, pero ya como territorio en "delirio" y un territorio de "silencio dormido”. De este modo, los espacios que van articulando un sustrato fronterizo, están tejidos a partir de una dinámica de encuentro y desencuentro de una sujeto múltiple que se origina como sujeto migrante. Aquella que realiza el viaje, desde el cual va incorporando en su experiencia cultural los elementos de una catástrofe oculta, que se va distendiendo por entre la escritura a través de los entrecruces de la pérdida y del vacío: "nadie tiene nada/ que decirle a mi noche"; de los "Weda pewma" (malos sueños), desde donde los sueños se escenifican en sombras que presagian un destino deshabitado: “... el sueño de mis hijos / de los hijos de mis hijos / en territorio de nadie"; y del naufragio como circunstancia de exilio y retorno hacia la muerte: "No recordábamos los motivos de este viaje /la razón oculta del naufragio".

En este sentido, el texto de Maribel Mora va ampliando la construcción problemática de la sujeto a través de un cuerpo cultural de junturas y rajaduras que transita constantemente "entre dos aguas" (como la misma poeta lo ha mencionado). De ahí se convierte en náufraga que deambula por los entre lugares del sueño y el cuerpo, es decir, es el cuerpo en el sueño y el sueño en el cuerpo, como lugares culturales que habitan un entre-medio árido: “...heme aquí, cuerpo y sueño / sobre este suelo baldío".

Este cuerpo fronterizo se va llenando y vaciando a la vez, hasta que se diluya la pulsión original (Gnechen $)^{14}$, es decir, hasta que acontezca la muerte en ella misma, y donde al mismo tiempo, la muerte se manifiesta como espacio consanguíneo, es "compañera", es "hermana" en sabiduría de los presagios de una huella delirante.

12 Texto inédito.

13 Se interpreta como un espíritu mítico femenino mapuche que vive en las lagunas. En esos lugares enamora a varones despreocupados y se los lleva a vivir a sus dominios.

14 Chao Gnechen / Ngüenechen: divinidad original y superior del pueblo mapuche. 
De esta forma, Maribel Mora va destrenzando en su escritura lugares de cruce cultural, de los cuales uno de los más significativos es el cuerpo como materialidad de la escritura, a través de dispositivos relacionales que convergen, no en una zona homogénea ni cerrada, sino más bien, en un enclave que explosiona frente al reconocimiento de los empalmes culturales que atraviesan las subjetividades corporales: "Es la Atlántida -nos dijimos-/ o la isla de los muertos/ ¿vendrá Ulises, Sumpall ${ }^{15}$ o Jesucristo?”. Esta manifiesta intertextualidad mítica trasluce una "conciencia fronteriza" que reitera el viaje, no lineal de la sujeto, sino hacia y desde un destino de concurrencia cultural desvariado, un destino complejo desde el cual enuncia su existencia corporal y subjetiva.

Cuerpo y cultura se funden en un proceso permanente de exclusión e inclusión, lo que intensifica el lugar de la enunciación. De esta forma entonces, el cruce se daría en el espacio del arrobamiento de un delirio en la construcción de la subjetividad de la sujeto por las experiencias a las que se arroja, pero también a las que está destinada a precipitarse. Maribel Mora plantea la posibilidad de la locura no como el lugar de la patología, sino como el desplazamiento de una sujeto consciente de sí misma que descubre en cada momento las represiones y las pérdidas que ha internalizado y así comprende las represiones y las pérdidas de su cultura como cuerpo vivo. Es el delirio de una subjetividad autónoma que traspasa el limbo del sujeto mapuche universalizado por las categorías occidentales. Por eso que la cultura "mestiza" que construye la experiencia de las identidades en el texto se hace y rehace como un lugar heterogéneo donde deambula la alucinación, el perrimontún ${ }^{16}$, ese acontecimiento inesperado que es la metáfora de la experiencia cultural propia del cuerpo de la sujeto y también la hendidura que posibilita el retorno a una cultura ancestral que la pulsiona alucinadamente por dentro, de ahí que la sujeto se contiene en el perrimontún de la propia escritura.

\section{ADRIANA PAREDES PINDA: EL (DES)PLACER DE UNA LENGUA MERETRIZ}

El texto poético $\ddot{U} i(2005)$ se inicia con una antesala narrativa señalando los dos grandes "cruzamientos" de la sujeto como sujeto "mestiza y/o fronteriza" ${ }^{17}$ : la oralidad (que ha

15 Shumpall o Chumpal: ser mítico, señor de las aguas. Se aparece como un hombre joven de cabellos dorados y vestiduras resplandecientes. Habita en lagunas, ríos, mares en donde seduce y rapta a doncellas mapuche, a quienes toma como esposas. En ocasiones paga por ellas con bienes provenientes de sus dominios (Jaime Luis Huenún, (ed.), La memoria iluminada: poesía mapuche contemporánea. Pelótuñma ngütrámtunzüngu: fachántü ta mapuche ñi ülkántumeken 400).

16 El Perrimontún, como lugar de experiencia cultural, hace alusión a visiones y experiencias alucinatorias o sobrenaturales que le ocurren a la persona que debe iniciarse como machi.

17 La noción de (conciencia) mestiza la recojo de Gloria Anzaldúa: “...a new mestiza consciousness, una conciencia de mujer. It is a consciousness of Borderlands". Para Gloria 
contenido tradicionalmente a la cultura mapuche) y la escritura: "Conversemos la sangre, nuestras hermandades y lejanías... / se me pierde aliento el hueco de la página". Por otro lado, al finalizar el primer verso en puntos seguidos, la poeta intenciona una continuidad y una fuga dentro la escritura. Es la manifestación de una fractura desde la posibilidad de un empalme, de un doblez cultural en la subjetividad que no se cierra. Algo sucede en la experiencia de la protagonista poética que establece relación con el adentro y el afuera (al mismo tiempo que ambos son el adentro y el afuera): “...ha encendido kutralwe ${ }^{18}$ allá donde antaño era el adentro y no el afuera, allá en el afuera en los cueros del alma allá y yo aquí...". Es la marca del peregrinaje que inicia la sujeto por entre su memoria cultural histórica y corporal y por entre la experiencia porosa y actual de su escritura. De esta manera, Adriana Paredes pone en escena la explosión del lugar de enunciación de la sujeto, exhibiendo una subjetividad que se construye en una deslocalización del cuerpo, en nombre de una tensión con lo que hay, porque lo que hay (la escritura como referente de una pérdida), aparece como falta de lo que hubo (la palabra): "Escribo porque no entiendo, solo la sombra de la sombra de un cometa de la cola de un cometa rozando el hueco de mi mollera vacía...". Este lugar corporal en experiencia está guiado por la angustia de la desposesión, la experiencia de un cuerpo exiliado que se cruza por entre la escritura que escenifica, a través de la escritura misma, la significación del cuerpo del exilio. Sin embargo, en este hundido vacío de la sujeto, se inscribe también la "juntura", no sin contradicción: "me he enamorado de la lengua castellana meretriz, me ha robado el mapuzungun, me ha robado el chezungun el ce sumun, me ha robado el espíritu, el aliento, el sentido..., por eso escribo bajo estado hipnótico y no logro zafarme; esta lengua meretriz me pesa, me quema..."19. La tensión dialógica que manifiesta Adriana Pinda

Anzaldúa la mestiza "es un producto de una transferencia..., en perpetua transición". Esto formaría su cultura comunicante: la juntura (a la vez rajadura). Y además este sería el lugar donde se dan poderes contradictorios lo que hace explosionar una nueva conciencia: "conciencia mestiza". Esto quiere decir que la mestiza no tiene un 'país', 'un territorio geográfico', sino que tiene un territorio propio (que es su experiencia). De esta manera, se convierte en sujeto 'culturizada' porque está participando en la creación de nuevas culturas. Así, la sujeto mestiza se transforma en espacio de una historia "otra" para decir el mundo y su participación en él (Bordelands/La frontera 100-102).

18 Kutralwe: fogón.

19 Para Derrida el robo de la palabra tiene una importante doble significación, porque por un lado está vinculada institucionalmente con el concepto de robo, del sustraer para imponer otro orden encima del que había y, por otro lado, también se articula al 'impoder' como lugar de explosión, de la potencia de un vacío: (La palabra) Soplada, esto es, sustraída ... para colocarla en un orden, orden de la verdad esencial o de una estructura real, psicológica o de otro tipo". Por ejemplo, la palabra del mundo mapuche actualmente ha sido exotizada y manipulada por los discursos de poder y también, históricamente se le ha impuesto un lugar de representación menor, localizándola dentro de un léxico 'popular y básico' dentro de la lengua española hablada en Chile. Más adelante, Derrida dice que "El robo es siempre de una palabra o de un texto, de una huella (por esto hay) que hacer volar en pedazos la estructura 
entre la palabra 'sustraída' y el placer de una palabra degradada, es la relación entre la palabra 'ocupada' y/o tachada por la institución de poder y la resignificación de esa misma palabra que se llena con la ausencia, con el vacío potenciador, desde donde surge la trayectoria de una escritura exiliada, "fronteriza" que zigzaguea por los entremedios de los alientos culturales de la subjetividad que se va diciendo, nombrando implícitamente mestiza ("escribo porque tal vez es cierto que tengo dos corazones").

Desde este espacio entre-escritural, Adriana Paredes instala el cuerpo desde donde enunciará el discurso poético de $\ddot{U} i$ la tragedia que potencializa la muerte como el foco de una impulso de aliento que nombra desde dentro, de una pulsión de textualización corporal conflictiva que se vuelve a abrir a la deslocalización, que es también una localización de la contradicción y de la producción de un territorio cultural descentrado de una sujeto mapuche trascendental.

\section{REFLEXIONES INACABADAS}

Desde una perspectiva inconclusa, las construcciones subjetivadas asumidas en contradicción y la responsabilidad de conciencias "fronterizas" expuestas en textos de estas poetas, no intentan significar una experiencia y una existencia no tensionada, sino que despliegan y señalan una subversión a la normatividad que apela a una 'marca' acomodada de sujetos identitariamente estables. Es también, por este mismo gesto insubordinado en sus escrituras, que las hace explícitamente sujetos inviables para cualquier sistema cultural homogeneizador.

Las escrituras de mujeres mapuche y de origen mapuche ${ }^{20}$ agencian, es decir, son responsables en diferentes sentidos de una conciencia crítica que aparece en sus escrituras

del robo ... Destruir del mismo golpe la metafísica, la religión, la estética, etc. ... y abrir así al Peligro un mundo en el que la estructura de la sustracción no ofrece ya ningún abrigo...". Por otro lado, agrega que esta intención desestabilizadora tiene otro deslizamiento: "El impoder..., no es como se sabe, la simple impotencia, la esterilidad del 'nada que decir' o la falta de inspiración. Por el contrario, es la inspiración misma: fuerza de un vacío, torbellino del aliento de alguien que sopla y aspira hacia sí, y que me sustrae aquello mismo que deja llegar a mí y que yo creo poder decir en mi nombre..., esta fecundidad del otro aliento es el impoder: no la ausencia sino la irresponsabilidad radical de la palabra, la irresponsabilidad como potencia y origen de la palabra. Me relaciono conmigo mismo en el éter de una palabra que siempre me es soplada y que me sustrae aquello mismo con lo que me pone en relación". (J. Derrida, "La palabra soplada", La escritura y la diferencia 241-2).

${ }^{20}$ Las poetas señaladas en este artículo no corresponden ni representan a todas las poetas mapuche contemporáneas, por ejemplo, también están: Sonia Caicheo, Ximena Ancamil, Rayén Kvyeh, Mónica Huentemil, Sandra Trafilaf, Jessica Cona, Angélica Reiñaco, Viviana Marilaf, entre otras. Algunas de ellas solo han publicado de manera ocasional en revistas, como las últimas cuatro. Para más información, ver Maribel Mora (6). 
desde diferentes (des)bordes, por un lado, de interpelación explícita y/o implícita a las construcciones culturales autocráticas sobre ellas mismas y por otro lado (y al mismo tiempo), de articulación a la cultura mapuche. Sus prácticas poéticas configuran una comunidad polifónica de voces escriturales, que despliegan emplazamientos poéticos de (re)unión con lo cosmovisional-ancestral ${ }^{21}$, hasta disposiciones desmitificadoras de la cultura y de unas identidades de esa cultura, reuniendo así una pluralidad cultural respecto a las identidades y las "políticas de localización” dentro de la cultura mapuche. De aquí entonces, una de las importancias de sus producciones poéticas como signos activos de procesos de conciencias y de experiencias. Este lugar de enunciación sitúa a las poetas y a sus expresiones literarias en el marco de unos deseos particulares y 'laterales' con la "cultura del texto", donde además, el acceso al texto escrito ha sido problemático y problematizado por lo que con ello contribuyen, aún más, a identificaciones cada vez más heterogéneas que intervienen el universo de la verdad consonante. Sin duda esto se origina, dentro de las producciones poéticas de las autoras, en la conciencia de experiencias que reconocen los mandatos por los que son registradas culturalmente y convierten sus vidas en inhabitables (Butler 17).

Las mujeres escritoras mapuche y/o de origen mapuche, aportan al conjunto de discursos escritos voces que construyen nuevas y diferentes subjetividades y, desde su posicionamiento genérico y cultural, dan forma a vivencias particulares asociadas a experiencias singulares y colectivas. Estas prácticas literarias constituyen un cuerpo escritural que se resiste y se niega a ser espacio de inscripción impuesto, para realizarse en un registro textual que señala la incursión en una historia "propia" 22 , la que surge de una memoria histórica, social y cultural también "propia", mostrando en y a través de sus intersticios, una ya reconocida relación problematizada entre cuerpo-subjetividadidentidad (sujetos en experiencia) y poder.

Dentro de este plano de tensiones es que el desdoblamiento poético de las mujeres mapuche se sitúa como una práctica cultural enhebrada a condiciones históricas y sociales que recorren el tiempo ancestral, a la vez que el tiempo de colonización (pasado y actual), produciendo fricciones y flujos que estallan en la escritura en diferentes sentidos y con diferentes grados de aproximación y de dislocación. Por esto mismo, sus realizaciones

21 En este sentido, por ejemplo, Adriana Paredes Pinda se inicia en una poesía bastante ligada a temas y estructuras occidentales, para luego ir girando hacia estrategias discursivas y temáticas más vinculadas a la cultura mapuche ancestral o tradicional, sin abandonar una enunciación problematizada. Esto da cuenta de que muchas de las poetas aquí mencionadas, entre otras; cruzan sus estrategias escriturales respecto a las construcciones tanto interculturales, como intraculturales.

22 Al decir "propia" no intento realizar un aislamiento de la experiencia o señalar una experiencia paralela a "otras". Sino que lo "propio" siempre se reconoce como tal, en el movimiento de interacción permanente entre sujetos y grupos culturales diferentes. Por lo que lo "propio" no es análogo ni homogéneo entre sujetos de una misma cultura y tampoco entre culturas, ya sean estas hegemónicas o de "alterización". 
poéticas, de igual forma, se apropian de diferentes posibilidades estéticas de la producción poética occidental, originando una nueva, diferente y propia respuesta estética y política dentro del sistema literario chileno. Así, la escritura de estas poetas se traduce en un gesto cultural de subversión de signos contenidos en el lenguaje, perfora y abre espacios (antes invadidos, cerrados y/o negados) de representación, enlazada a los repliegues propios de su lengua ${ }^{23}$, de sus historias y de sus experiencias. Los dilatados bordes que envuelven este espacio poético se hacen múltiples en el (des)nudamiento de una contextualidad histórica y literaria, dejando entre-ver la raíz plural de su enunciación. De esta manera, el lector y/o lectora tienen la posibilidad de entrar en complicidad (abrir su conciencia), con una palabra poética diferente y propia. Intima con el repliegue y despliegue de terrenos metafóricos, que no se inician en supuestos de una poesía 'femenina' mapuche enquistada a estereotipos de los sistemas patriarcales y hegemónicos, ni tampoco en una escritura que representa espacios para desatorar un 'enigma' étnico; sino que trasluce los contornos y sustancias de una lengua poética en alteridad respecto a la práctica de la poesía en general y que tiende a la expansión de todas sus posibilidades, a partir de sus múltiples enunciaciones y de las diversas estrategias discursivas.

Es desde este "fuera de lugar" 24 que las poetas mapuche intervienen y modifican estructuras de funcionamiento social, en un espacio donde su discursividad poética no tiene "historia de inscripción".

Las mujeres mapuche en el acto de situarse como agentes de discursos poéticos y como referentes múltiples dentro de los espacios escriturales, ponen también en crisis anquilosadas oposiciones de nuestra construcción cultural: los binarismos masculino / femenino y chileno / mapuche, porque las poetas indagan e interrogan los cruzamientos de subjetividades textuales diferentes que se construyen en la escritura. Por lo mismo, no es solo el discurso poético (y literario) producido por mujeres mapuche el que exhibe esta

23 Sabemos que la lengua es la manera en cómo nos decimos (y decimos al mundo y a los demás) y cómo experienciamos en y con el mundo. Por lo tanto, me refiero a su lengua en el sentido de que, aunque el mapuchezungún fue prácticamente borrado del pueblo mapuche, aún persiste como lengua y como impresión interna (pensamiento) en la construcción de mundo. De aquí que muchos poetas mapuche (mujeres y hombres) escriban en mapuchezungún o recurran a la interacción entre una y otra lengua, inaugurando de esta forma una estrategia poética diferente que da cuenta de una apropiación consciente de la escritura, no solo como sustrato estético, sino que también, como dispositivo de comunicación, de construcción de cultura, de reivindicación, de emplazamiento político y de intervención y de ampliación en la práctica literaria en general.

24 Al hablar de los cuerpos, las subjetividades, las identidades y sus producciones fuera de lugar, lo planteo en el sentido dado por Stuart Hall, quien alude que 'el otro' es aquel que ya no está donde 'debiera estar' (según los sistemas colonialistas), por lo que estaría fuera de control, en "The Local and the Global: Globalization and Ethnicity", en Anthony D. King (ed.), Culture Globalization and the World-System. Contemporary Condicions for the Representation of Identity (39). 
crisis, sino que toda práctica que, en su puesta en discurso, posibilite las emergencias de zonas y espacios ausentes o invisibilizados del pacto social patriarcal-colonialista chileno, contribuye a derribar dichos fundamentos de oposición, como ocurre también en estos momentos, con los discursos públicos políticos de las mujeres mapuche e indígenas en general, en Chile y en América Latina.

Dentro de esta disposición, la recepción emerge como un lugar imprescindible que pone en movimiento acciones dialogantes a partir, fundamentalmente, de una perspectiva de lectura encaminada a liberar los sentidos y propuestas de una producción escritural, legitimándola como una práctica e interlocución efectiva con su contemporaneidad y con la(s) historia(s) ${ }^{25}$. En este sentido, y pensando en el contexto de esta producción, el problema de la recepción de la poesía escrita por mujeres mapuche se desplaza desde el producto objeto (el libro), hacia el lugar de género y hacia la situación cultural de la sujeto productora del texto, lo que complejiza su circulación al ingresar a las redes de las distribuciones del poder de los discursos.

Las poetas mapuche y de origen mapuche, por los modos de concebir las relaciones entre escritura y producción de significaciones, por la decodificación de mandatos genéricos, por la crítica a las representaciones asignadas, que la mayoría de las poetas mapuche ejercita en su práctica poética, y por la emergencia de sus escrituras en un determinado momento histórico, configuran el lugar de una producción en proceso abierto a nuevas y otras lecturas. Por lo tanto, escenifican un 'corpus' o 'comunidad' de prácticas poéticas que, en sus diferencias, simboliza la heterogeneidad como huella escritural de una escena emergente.

La poesía escrita de mujeres mapuche es aún un producto 'informal' en la economía cultural chilena. Sus discursos poéticos (y en general, sus discursos), siguen sin 'aval' ni legitimación como productores de debate estético y político en el contexto con que establecen sus relaciones de tensiones, complacencias y/o disidencias.

En este sentido, el problema de la recepción de la poesía escrita por mujeres mapuche se desplaza, como ya se mencionó antes, desde el producto objeto hacia el lugar cultural de la sujeto que produce el texto, por lo que están más al borde que cualquier escritura de mujeres "no indígenas". En este sentido, este 'estatus' (por cierto, desde un lugar canónico y exclusivo) de las producciones poéticas escritas por estas mujeres, habita más allá de la marginalidad respecto a la competencia intelectiva que se opera en el funcionamiento de cualquier discurso público. Sus aportes siguen estando al margen de las discursividades que manejan y manipulan los pactos de poder.

25 Al hablar de "historia(s)" no hago alusión a la "historia oficial", ni a historias "paralelas" (mapuche-chilena), sino que mi interés es aproximativa a la historia como experiencia, por lo tanto, en movimiento y dentro de diferentes contextos culturales, políticos y sociales. Historias que coexisten, interactúan y se tejen permanentemente construyéndose, reconstruyéndose, significándose y resignificándose. 
Sin embargo, y a pesar de lo anterior, esta práctica poética de mujeres se constituye como un lugar y una perspectiva de producción cultural que hace comparecer unos márgenes, situando la visualidad de un discurso que escapa al orden normativo y homogeneizador de las "alteridades". Lugar desde el cual es posible conocer y comprender vivamente la cultura mapuche contemporánea, como confluencia del lenguaje escrito y oral con las realidades sociales, políticas e históricas. Esto apunta a (des)tejer el conocimiento y el sentido, considerando las experiencias y las formas de entender y representar los lugares simbólicos desarrollados dentro de las diferentes tradiciones culturales mapuche y que, en diferentes grados, complejidades y estrategias, las poetas despliegan en los textos. En este sentido, podemos emplazarnos en una escritura y una lectura que están sostenidas desde unas configuraciones críticas desarrolladas dentro de las producciones poéticas de mujeres mapuche y que no incumben solamente a éstas, sino que implican la transformación de valores y de sistemas de representación. El sistema social y teórico en general organiza diferencias y las distribuye según una escala de valores e intereses de poder. Esta figuración centrista de la diferencia constituye la impugnación de la subjetividad de las mujeres mapuche y el resultado de ello es una discriminación múltiple: de clase, de género y de etnia. Por esto entonces, la diferencia se ha dispuesto, dentro de las jerarquías, como una manera de enfatizar cierta 'inferioridad' de las personas y del pueblo mapuche y de ahí entonces, cierta 'inferioridad' de sus producciones. Esta visión de la "diferencia" se apoya en supuestos naturalistas respecto a las mujeres mapuche, en relación con las representaciones contemporáneas que se han construido sobre ellas y que refuerzan la dicotomía mujeres buenas/mujeres malas y el estereotipo de lo exótico, que ciertamente excluyen o ejercen una borradura de los valores culturales en juego. Esta partición de oposición y de imagen impuesta a las mujeres mapuche, obviamente, sirve a intereses dominantes en el contexto histórico que actualmente se vive en particular y, en general, en América Latina. Esta dicotomía responde, entonces, al propósito de definir identidades nacionales y sustanciar una 'ciudadanía integrada', como también mantener jerarquías sociales, políticas, sexuales, de género, de clase, de etnia y culturales. En este sentido, las normas que el sistema chileno utiliza para apoyar esta homogeneización y falsa inclusión son la educación, la religión, el discurso político ("de integración” y "de protección”) y los medios de comunicación. Esta representación o norma de construcción de subjetividades generaliza y/o abstrae imágenes de mujeres mapuche dentro de una linealidad preconcebida, donde la diferencia que se naturaliza resulta necesaria para alimentar la autoridad de 'uno', en relación con un supuesto de sujeto único-activo. Este presupuesto de diferencia, se transforma en una necesidad estructural de un sistema que funda las diferencias como oposiciones y con lo que se legitiman las normas, el modelo "normal" y donde se genera una alianza entre racionalidad mascultista-colonialista y violencia, tanto institucional como cultural.

Dentro de todo este contexto de represión, la poesía de mujeres mapuche empuja intencionadamente a repensar el vínculo entre identidad, poder y comunidad, impugnando una representación inadecuada de las identidades. Es decir, la producción poética de mujeres mapuche permite situar y hacer ver unas diferencias. Diferencias que instalan realidades agenciadas, tanto materiales (libros, escrituras, cuerpos), como intelectuales (discurso, poesía) y que permiten a las poetas mapuche producir significaciones 
alternativas para expresar otras formas de conocimiento y experiencia. En este sentido, las poetas mapuche mantienen abiertos los lugares de indagación estética, de crítica y de resistencia. De aquí entonces, que la propuesta poética de mujeres mapuche se localiza en la subversión de la diferencia, (des)tejiendo identidades a través de experiencias en cultura, en historia, en movimiento, y agenciadas, es decir, y en palabras de Martha Sánchez Néstor: "Las mujeres indígenas no estamos disputando la representatividad ni los derechos de nadie, estamos construyendo nuestra propia identidad indígena, de mujer,... dando rostro a nuestra palabra, haciendo la otra historia que es también una responsabilidad y (es un) compromiso..." (Sánchez 4).

\section{BIBLIOGRAFÍA}

Anzaldúa, Gloria. Bordelands/La frontera. San Francisco: Aunt Lute Books, 1999.

Bhabha, Hommi. El lugar de la cultura. Buenos Aires: Ediciones Manantial, 2002.

Butler, Judith. Deshacer el género. Barcelona: Paidós, 2006.

Derrida, Jacques. "La palabra soplada". La escritura y la diferencia. Barcelona: Anthropos, 1989. 233-270.

Falabella, Soledad; Alison Ramay; Graciela Huinao, (edit.). Hilando la memoria. 7 mujeres mapuche. Santiago: Cuarto Propio, 2006.

Hall, Stuart. "The local and the global: Globalization and Ethnicity". D. King, Anthony (ed.), Culture Globalization and the World-System. Contemporary Conditions for the Representation of Identity. Macmillan-State: University of New York at Binghamton, 1991. 19-39.

Huenún, Jaime, (ed.). La memoria iluminada: poesía mapuche contemporánea. Málaga: CEDMA, 2007.

Kristeva, Julia. Sentido y sinsentido de la rebeldía. Literatura y psicoanálisis. Santiago: Cuarto Propio, 1999.

Miranda Rupailaf, Roxana. Pu llimeñ ñi rulpázuamelkaken. Seducción de los venenos, Santiago: LOM Ediciones, 2009.

Mora Curriao, Maribel. Perrimontún (inédito)

"Poesía mapuche: la instalación de una mismidad étnica en la literatura chilena". Ensayo para el Seminario de Estudios Latinoamericanos de Magíster en Literatura Chilena e Hispanoamericana, Universidad de Chile, 2007.

Paredes Pinda, Adriana. Üi. Santiago: LOM Ediciones, 2005.

Sánchez, Martha (comp.). La doble mirada: voces e historias de mujeres indígenas latinoamericanas. México: ILSM - UNIFEM, 2005.

Palabras Clave: poesía, mapuche, diferencia, género, subjetividades fronterizas.

KEY WORDS: poetry, Mapuche, difference, gender, bordelands subjectivity. 